\title{
Heat Transfer Augmentation Using Water-in-Glass Evacuated Tube Coupled with Parabolic Trough in Rack Dryer in the Drying of Capsicum Frutescens
}

\author{
Selvakumar Pandiaraj ${ }^{1 *}$, Tamilvanan Ayyasamy ${ }^{1}$, Kumaresan Govindasamy ${ }^{2}$ \\ ${ }^{1}$ Department of Mechanical Engineering, Kongu Engineering College, Erode 638 060, India \\ ${ }^{2}$ Department of Mechanical Engineering, Bannari Amman Institute of Technology, Erode 638 401, India
}

Corresponding Author Email: kecselvakumarp@gmail.com

https://doi.org/10.18280/ijht.380416

Received: 17 August 2019

Accepted: 10 October 2020

\section{Keywords:}

solar rack dryer, capsicum frutescens, evacuated tube, passive heating, exergy

\begin{abstract}
Open drying is practiced for drying Capsicum frutescens in the cottage industries of India. In order to improve drying, an experimental set-up of solar rack dryer is constructed and studied different heat transfer augmentation techniques. A passive heating coil extended from the header of a water-in-glass evacuated tube coupled with parabolic trough is used to augment the heat in the collector section of the dryer. The drying rate in rack dryer is found to be $62 \%$ higher than that of open air drying of green chillies. Moreover, the drying rate in augmented rack dryer is found to be $7 \%$ higher than that of rack dryer. In addition to this, an effective design for the dryer cabinet with respect to air circulation is arrived through computational fluid dynamics analysis. Through this new design, the drying rate is improved further by $3 \%$. Based on energy analysis, the specific energy consumption during the drying of this particular product using the augmented dryer is found to be 1.27 $\mathrm{kWh} / \mathrm{kg}$. The exergy efficiency of the drying chamber is found to be in the range of $4 \%$ $45 \%$ with an average of $16 \%$ for Capsicum frutescens.
\end{abstract}

\section{INTRODUCTION}

The solar energy existing out from the sun in the form of radiation can be used for several applications such as heating, drying, desalination, etc. [1]. An excellent way to preserve food is drying and solar dryers are found to be appropriate for food preservation industries in a sustainable manner. However, being unprotected from rain, wind-borne dirt and dust, infestation by insects, rodents and other animals, edible products may be seriously degraded to the extent [2]. Sometimes, they become inedible and the resulted loss in food quality may have adverse economic effects. Solar dryers use eco-friendly energy to dry the agricultural products, but the climatic changes impose challenge to the drying process. The crop drying technologies [3-6] have been studied by many researchers. The designs of solar air heaters [7] play a major role in the performance of dryers. The cottage industries in the rural area utilize natural convection solar dryers [8] without any heat transfer augmentation method. In indirect mode of solar dryer [9], the solar collector and the drying chamber are available as separate units. It is found that the natural convection solar dryers developed for drying fruits [10] perform well during bright sunshine hours. Certain crops are subjected to continuous drying process until desired moisture content is reached. In order to store the agricultural products for longer period of time, the role of solar dryers become vital [11]. Ambient air humidity is also an important factor that affects the quality of agro products [11]. Solar dryer with added accessories can improve the drying rate of agro products. As the price of the agro products depend on their quality, the need for solar dyers is essential for agro industries [12]. A thermal storage unit is required additionally for continuous drying process. Solar air heater is another important component of the dryer which contributes to quality drying. The classification of solar air heaters based on several parameters is given by Tyagi et al. [13]. A packed bed thermal storage $[14,15]$ is developed and the performance of the solar dryer is studied by Jain. Use of phase change materials for heat storage seems to be good for continuous drying process, but alternate technologies should be devised for drying certain crops under controlled conditions. Chilli is an important cash crop for many countries. Hossain et al. [16] have optimized a solar tunnel drier which is used for drying chillies without colour loss. The performance of natural convection solar dryers is found to be low because of low buoyancy induced air flow inside the driers. Solar dryer assisted by evacuated tube air collector is studied experimentally by one of the researchers [17]. Large scale drying of chilly is carried out using greenhouse type solar dryer [18] in Thailand, but the loss in quality is not ensured. Srisittipokakun [19] has studied the performance of parabolic shaped solar tunnel dryer for drying Andrographis paniculata. Heat transfer during the drying operation would occur through the flow of heat as a result of conduction, convection and radiation. Conduction heat transfer occurs within the absorber plate and convection occurs between air and absorber plate. Radiation heat transfer is considered for heat transfer from sun to the solar dryer. Mass transfer during the drying of wet solid would depend on two mechanisms, namely evaporation of moisture from the surface and migration of moisture from the interior of a particle to the surface. Evacuated tubes with parabolic trough [20] can be used for medium temperature solar applications. For augmenting the thermal stratification in the dryers, evacuated tube coupled with parabolic trough can be integrated to the dryer. This is experimentally tested and reported in the current study. 


\section{METHODOLOGY}

The major components used in the dryer are cabinet, trays, flat plate absorber and an evacuated tube fitted with parabolic reflector. A cabinet of $90 \times 43 \mathrm{~cm}$ was built with wood and the walls are insulated with glass wool. This cabinet is mounted over a stand of height $1.5 \mathrm{~m}$. The front, top and side views of the cabinet with collector are shown in Figure 1.

Provisions are provided inside the cabinet for placing the trays. Two trays of size $85 \times 40 \mathrm{~cm}$ are fabricated and kept inside the cabinet. A flat plate collector with absorber is attached to the cabinet through which air flows. It is inclined in such a way that the maximum solar radiation falls over the collector and sufficient draft exists. Evacuated tube coupled with parabolic trough is designed based on the research work of Selvakumar et al. [14]. The dimensions of the parabolic trough are given in Table 1.

The front view of parabolic trough is shown in Figure 2. Borosilicate glass evacuated tube of length $1500 \mathrm{~mm}$ and diameter $47 \mathrm{~mm}$ is used in the experiment.

A specially designed header with heating coil is fixed at the top of the evacuated tube. This evacuated tube set-up is kept at the focal point of the parabolic reflector and the heating coil protrudes into the inclined flat plate collector. The design of the evacuated tube header is shown in Figure 3.

Table 1. Dimensions of parabolic trough

\begin{tabular}{ccc}
\hline S.No. & Parameters & Dimensions \\
\hline 1. & Focal point & $15 \mathrm{~cm}$ \\
2. & Span & $60 \mathrm{~cm}$ \\
3. & Length of the curve & $68.87 \mathrm{~cm}$ \\
\hline
\end{tabular}
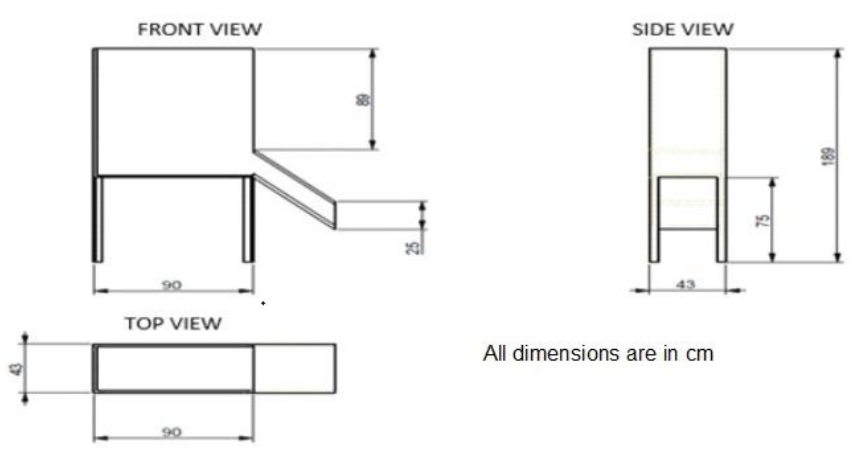

All dimensions are in $\mathrm{cm}$

Figure 1. Different views of solar dryer with dimensions

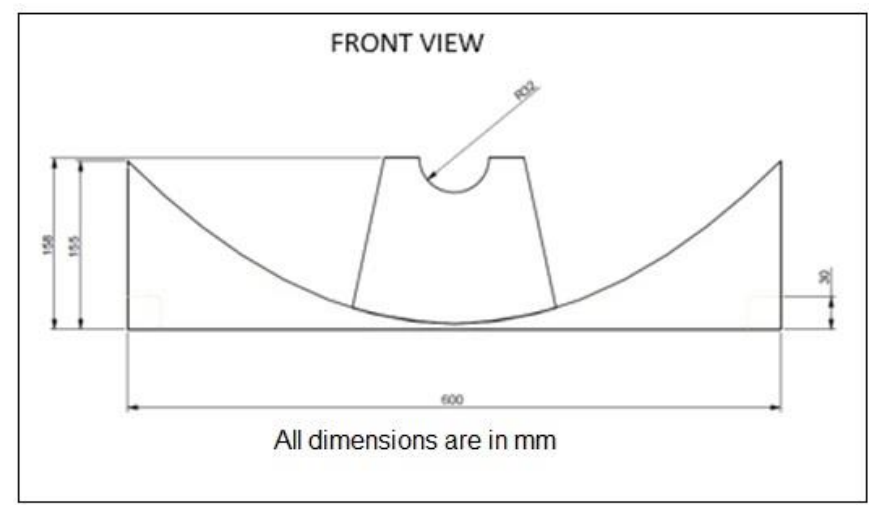

Figure 2. Front view of parabolic trough

The header has three ports and one of the ports is used for filling the evacuated tube with water. The other two ports serve as inlet and outlet for the heating coil. Aluminium is used for the fabrication of header. Water may be replaced with the other heat transfer fluids and experimental studies can be done with the same set-up. The scheme of experimental set-up is shown in Figure 4 and its photographic view is shown in Figure 5.

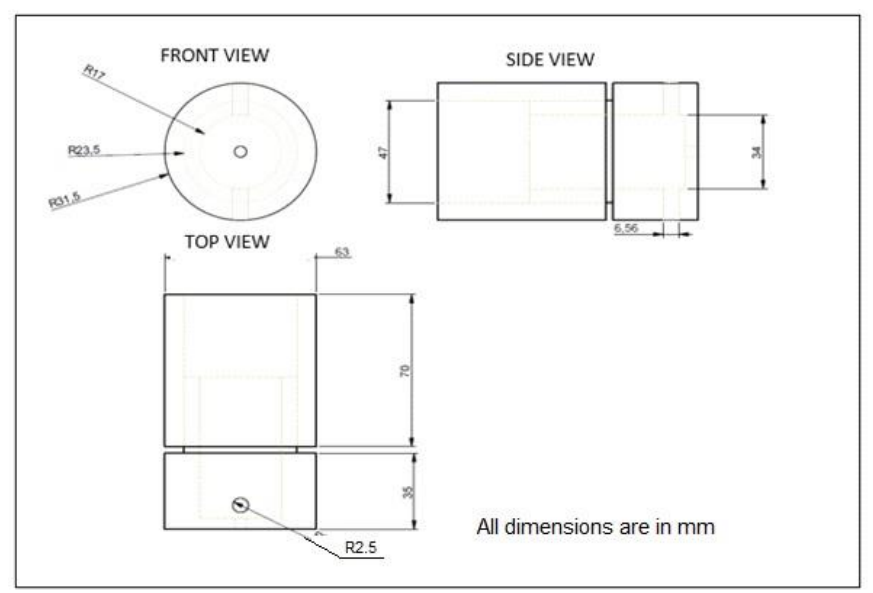

Figure 3. Design of header

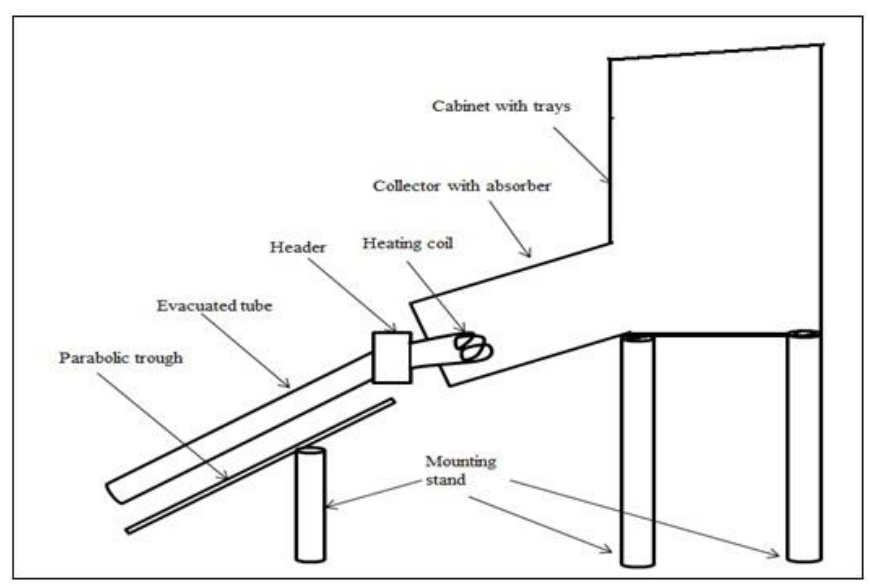

Figure 4. Schematic of experimental set-up

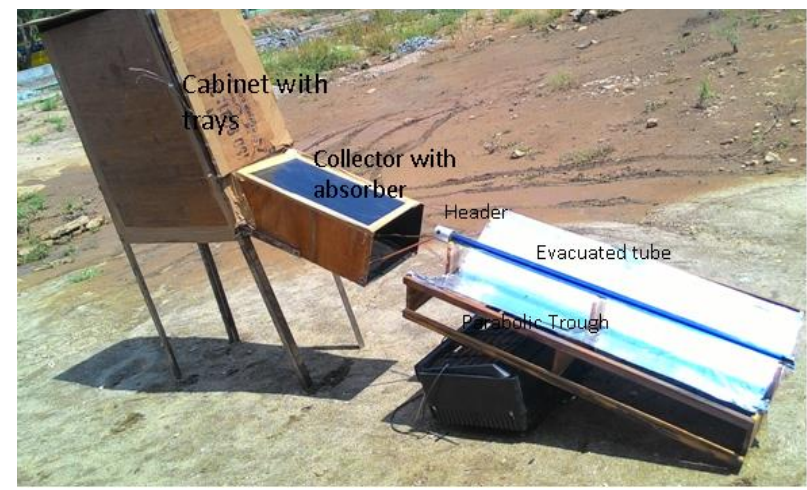

Figure 5. Photographic view of experimental set-up

The experimental set-up is exposed to sunlight facing northsouth direction. The experimental set-up was kept in front yard of the Renewable Energy Laboratory at Kongu Engineering College, Erode, Tamilnadu, India. Experiment is conducted to study the performance of the dryer. The absorber plate of the flat plate collector receives solar radiation through a glazing. Air flows through the gap between glazing and absorber plate. It absorbs the heat from absorber plate and the direct radiated 
heat from the sun. Natural draft is created due to thermal buoyancy and the hot air is moved towards the cabinet and trays. Initially, half $\mathrm{kg}$ of Capsicum frutescens is taken for the experiment and it is filled equally in the two trays kept inside the cabinet. Hot air flowing out from the collector absorbs the moisture from the chillies kept in the trays. The moisture content is determined by wet basis as reported by Fudholi et al. [21]. The same quantity of chillies is dried in the open air for comparing the drying rate with that of the newly developed system. In another experiment, the parabolic trough and evacuated tube are removed from the rack dryer and drying rate is recorded during the same period of time. Relative humidity is measured with the help of humidity meter and the temperatures are measured with thermocouples which are tested for their response time and it is found to be 62 seconds. The ambient temperature, surface temperature of the absorber and temperature inside the drying chamber are recorded. Further, the temperature at the inlet and outlet of the headers are measured. The drop in mass of the green chillies indicates the quantity of moisture removed. Relative humidity in the ambient air and inside the cabinet is measured with the humidity meter.

\section{RESULTS AND DISCUSSION}

\subsection{Drying rate results}

The readings from the experimental set-up are taken at an interval of 30 minutes from $10.00 \mathrm{AM}$ to $4.00 \mathrm{PM}$. The variations in ambient temperature and relative humidity are shown in Figure 6.

The ambient temperature is found to be maximum at 1.30 PM and the relative humidity varies between 30 and 32\%. Figure 7 depicts the solar radiation that prevails during the experimentation which varies between 600 and $1200 \mathrm{~W} / \mathrm{m}^{2}$ and found to be the maximum at 12.30 PM. After 2.00 PM, the solar radiation gradually gets decreased. The weight of the chillies gets reduced because of the continuous hot driven by the heating coil. During the starting time of experiment, the water temperature at the inlet of heating coil is found to be $42^{\circ} \mathrm{C}$. It reaches a maximum of $94^{\circ} \mathrm{C}$ at a peak radiation of $1200 \mathrm{~W} / \mathrm{m}^{2}$ between 12.30 and 1.00 PM.

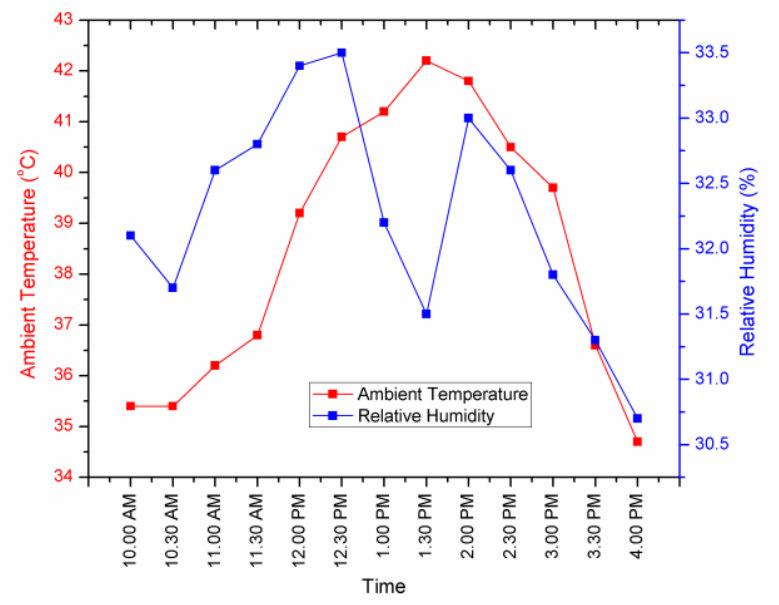

Figure 6. Variation of ambient temperature and relative humidity during experimentation

The chillies are dried simultaneously in open air, rack dryer and augmented rack dryer. The weight of the chillies is noted at every 30 minutes interval. The loss in weight of the chillies is the indicator for moisture removal process [22]. The variations in weight of the chillies during the experimentation in three different modes are compared in Figure 8.

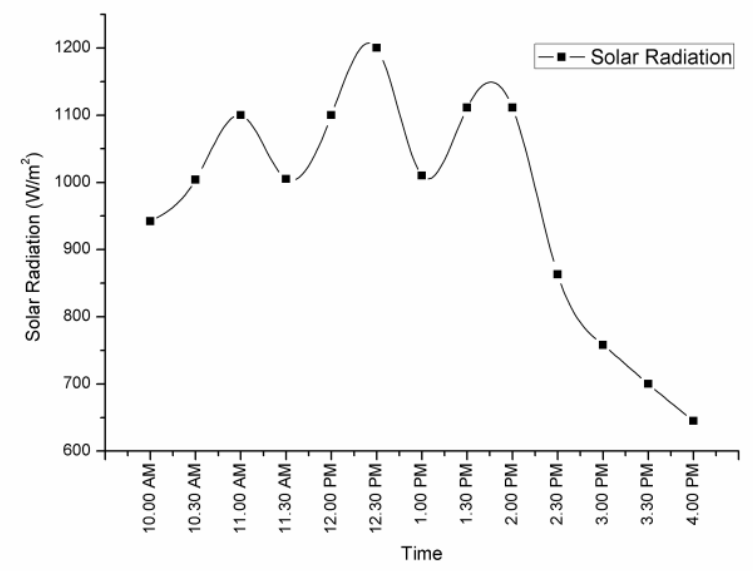

Figure 7. Variation of solar radiation during experimentation

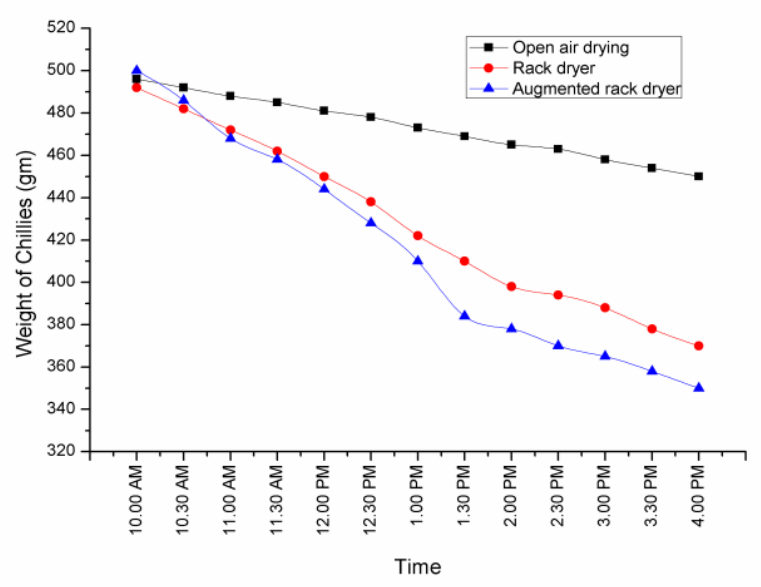

Figure 8. Variation in weight of the chillies during experimentation
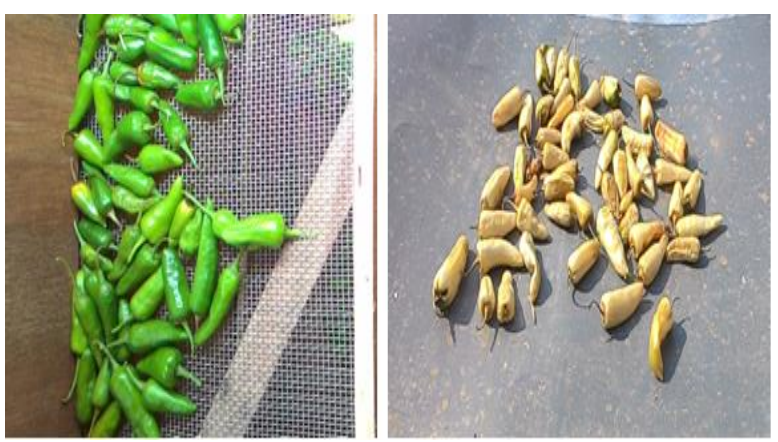

Figure 9. Photographs of green and dried chillies

The weight of the chillies in rack dryer is reduced from 500 to 370 grams whereas in augmented rack dryer it is reduced to 350 grams. In comparison to open drying, the drying rate of the chillies is found to be $69 \%$ more in augmented dryer. The photographs of green and dried chillies are shown in Figure 9.

The instantanoues efficiency for evacauted tube filled with water is plotted in Figure 10. The various temperatures recorded during the experimentation are shown in Figure 11. Efficiency of parabolic trough collector coupled with 
evacuated tube with water as heat transfer fluid is calculated as in the study [20] and it is found to be $39 \%$.

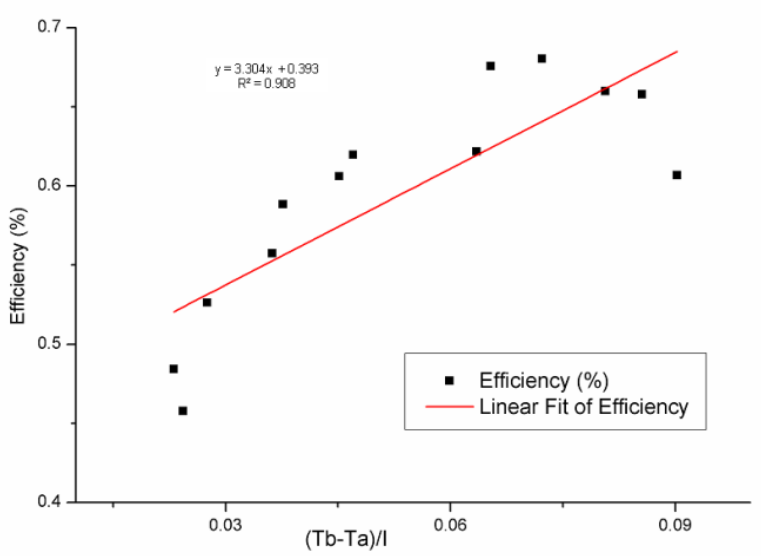

Figure 10. Instantaneous effciency curve

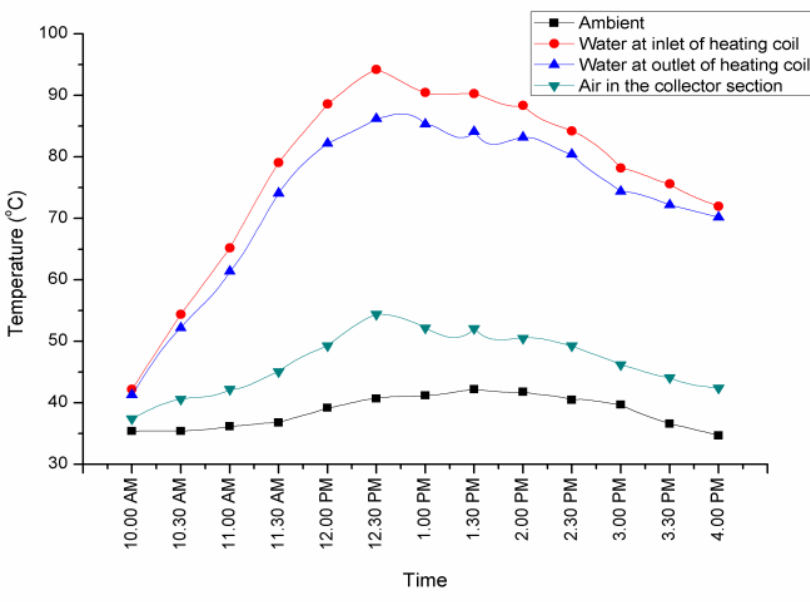

Figure 11. Temperatures recorded during experimentation

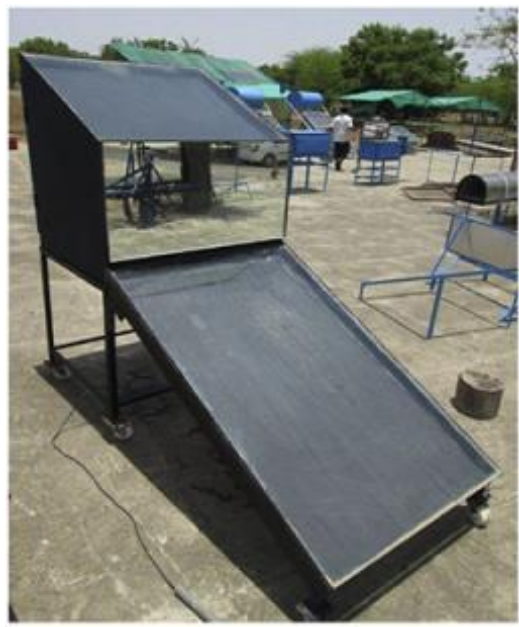

Figure 12. Conventional rack dryer by Dilip and Pratibha [5]

The average ambient temperature is found to be $38^{\circ} \mathrm{C}$. The temperature of air in the collector section reaches maximum of $55^{\circ} \mathrm{C}$ at $12.30 \mathrm{PM}$. The movement of air inside the cabinet is not found to be satisfactory. An analysis is performed to identify an improved design of the cabinet with the help of computational fluid dynamics software. In the early researches, an inclination is provided on the top side for better air draft as shown in Figure 12.

\subsection{CFD analysis}

In the above type of design, the air gets trapped in the bottom portion of the cabinet. This is observed through CFD analysis. Gambit package is used for modelling and meshing of geometry. FLUENT solver was used for post processing. Based on the experiments, the required boundary conditions are assigned for the above-said analysis. The meshed geometry of the existing set-up is shown in Figure 13. The inlet velocity is assigned as $1.7 \mathrm{~m} / \mathrm{s}$ based on an experimental reading taken using forced convection mode. This velocity value is assigned only to capture the pathlines clearly during the CFD analysis.

The flow path is simulated for the existing as well as modified set-ups. In the modified set-up, the inclination is provided at the bottom portion of the cabinet so that the air does not get stagnant at the bottom section. The pathlines of air are captured during the post processing of computational fluid dynamic analysis. The pathlines of air in augmented rack dryer is shown in Figure 14. A stagnant swirl of flow is seen at the bottom of the augmented rack dryer. In Figure 15, pathlines inside modified augmented rack dryer is depicted. The bottom wall of the augmented rack dryer is made parallel to the incoming air passage. The stagnant swirl is not seen in the augmented rack dryer with modified flow path. The actual set-up is modified and experiments are conducted with the same range of solar radiation. The drying rate is found to be increased by another $3 \%$ due to the elimination of stagnant air at the bottom portion. The loss of weight observed during the experimentation is shown in Figure 16. Nearly, 46 grams of weight is lost during open drying from 10.00 AM to 4.00 PM. For the same period, the weight losses in rack dryer and augmented rack dryer are found to be 122 and 150 grams respectively. In the augmented rack dryer with modified flow path, the weight loss is found to be 163 grams during the same period of time.

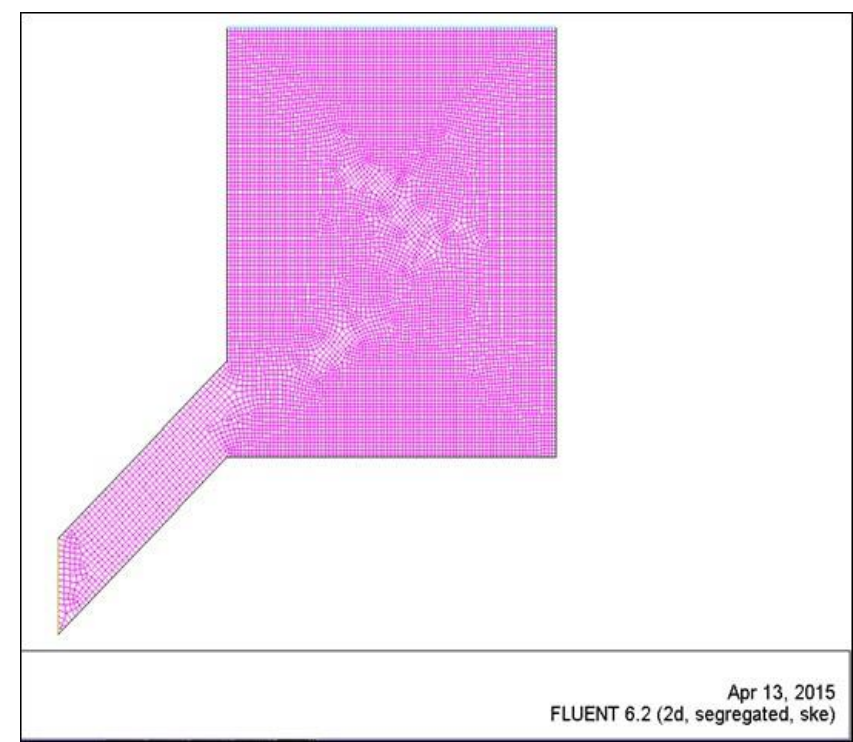

Figure 13. Meshed geometry 


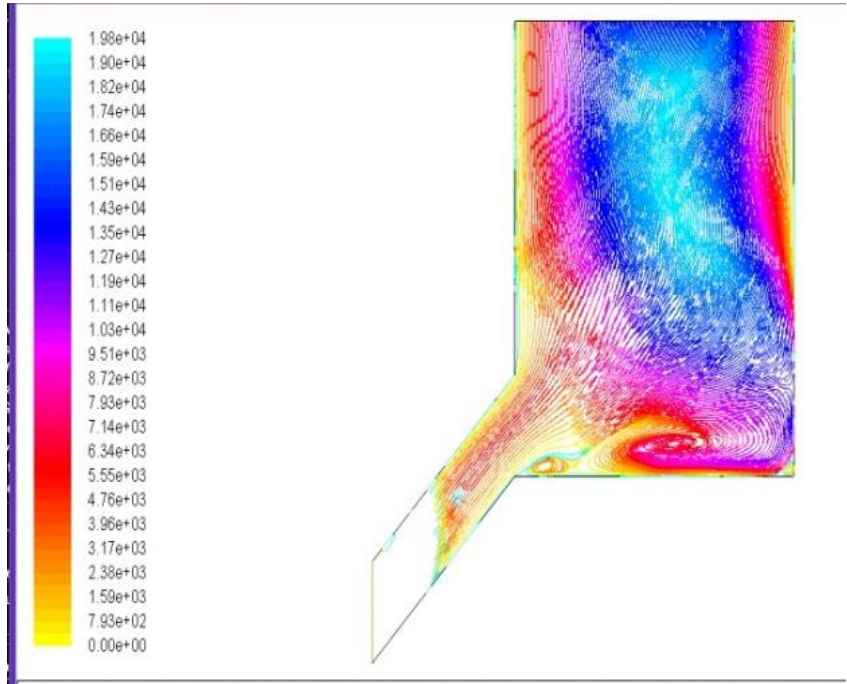

Path Lines Colored by Particle ID

FLUENT 6.2

(a)

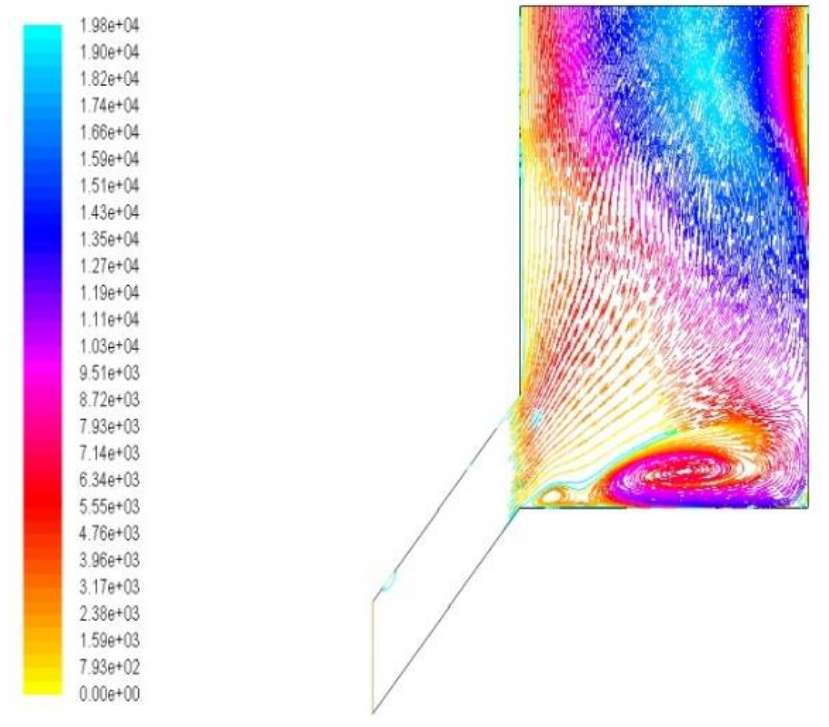

Path Lines Colored by Particle ID

FLUENT!

(b)
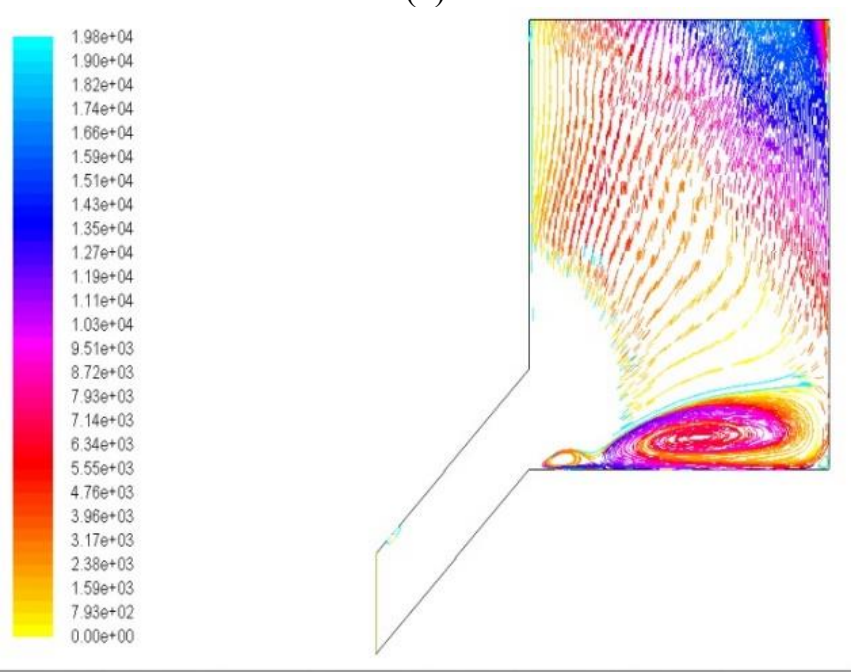

Path Lines Colored by Particle ID

(c)

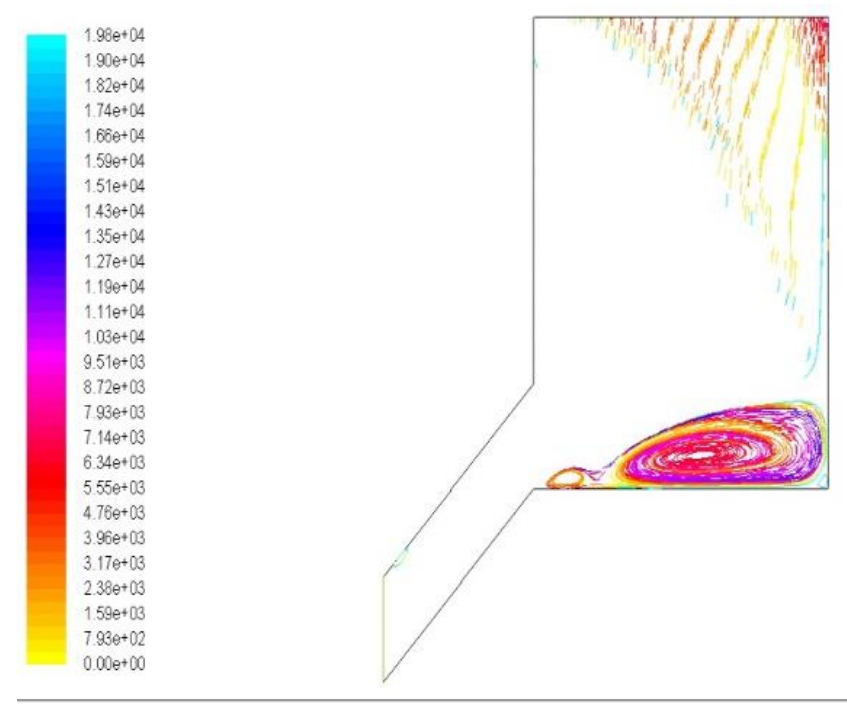

Path Lines Colored by Particle ID

(d)

Figure 14. Air flow path in the existing set-up

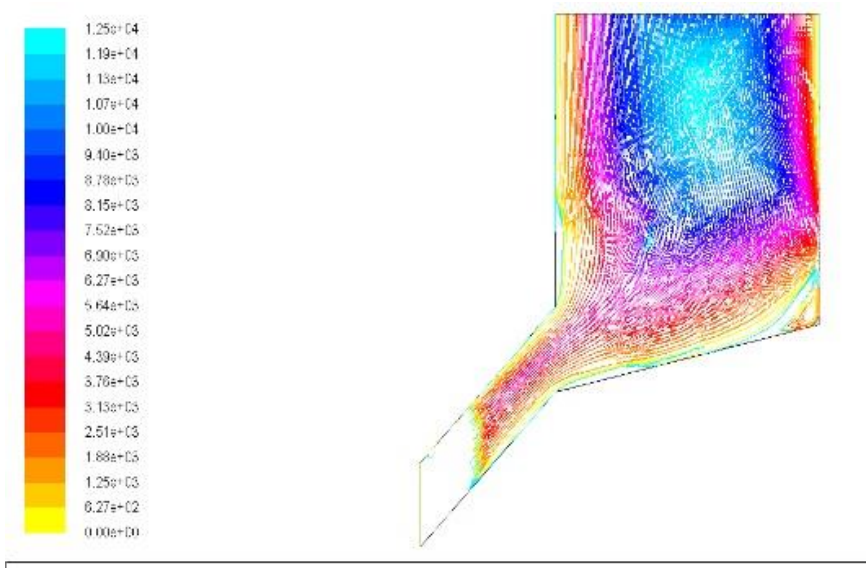

Path Lines Colored by Particle ID

FLUI

(a)

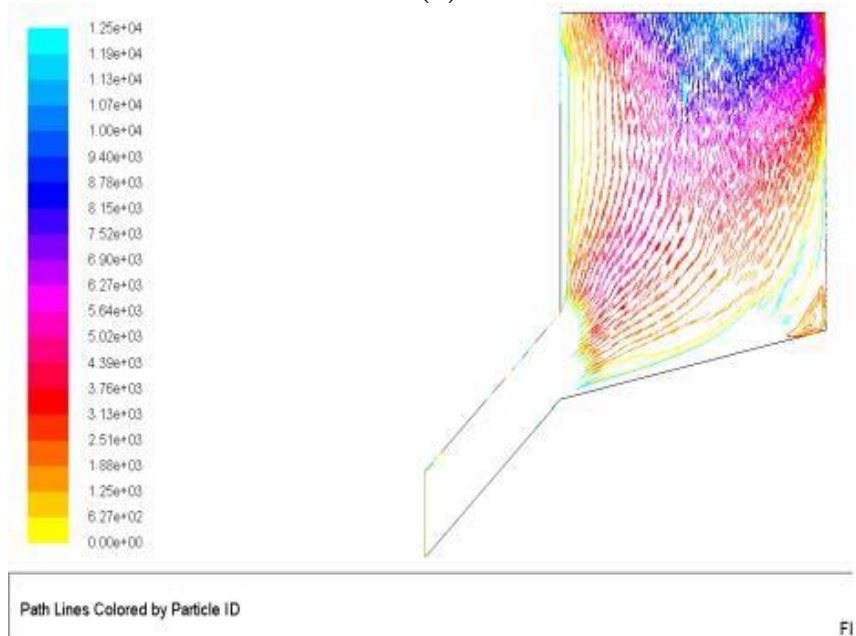

(b) 


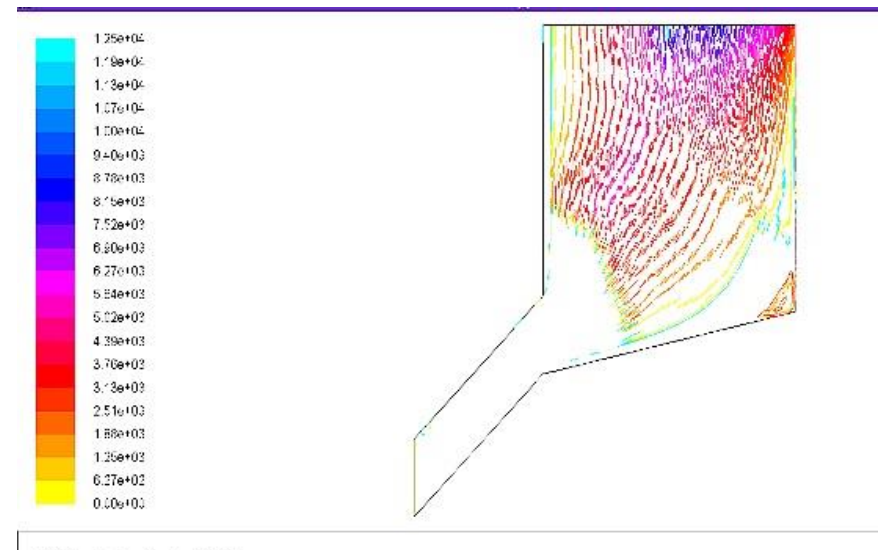

Path Lines Colored by Particle ID

(c)

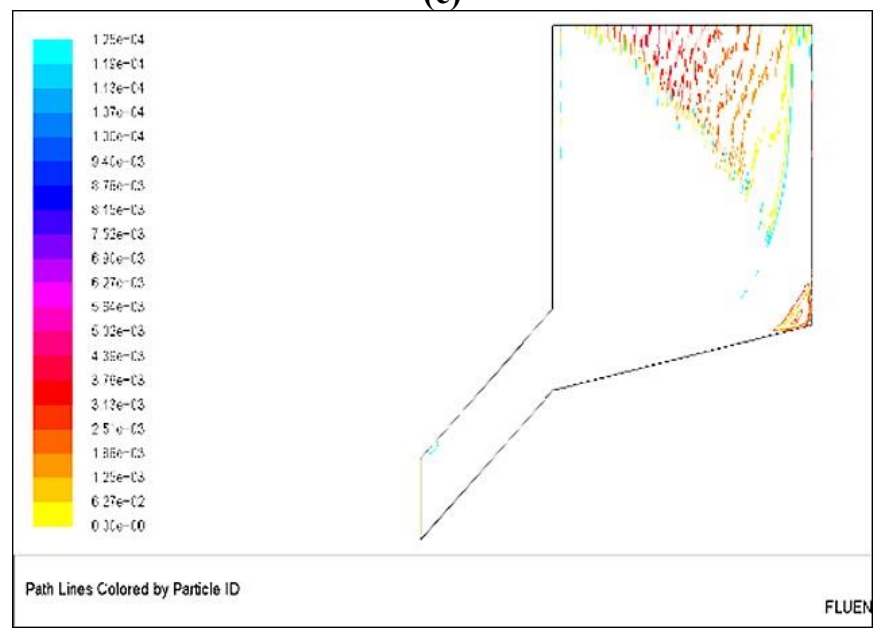

(d)

Figure 15. Air flow path in the modified set-up

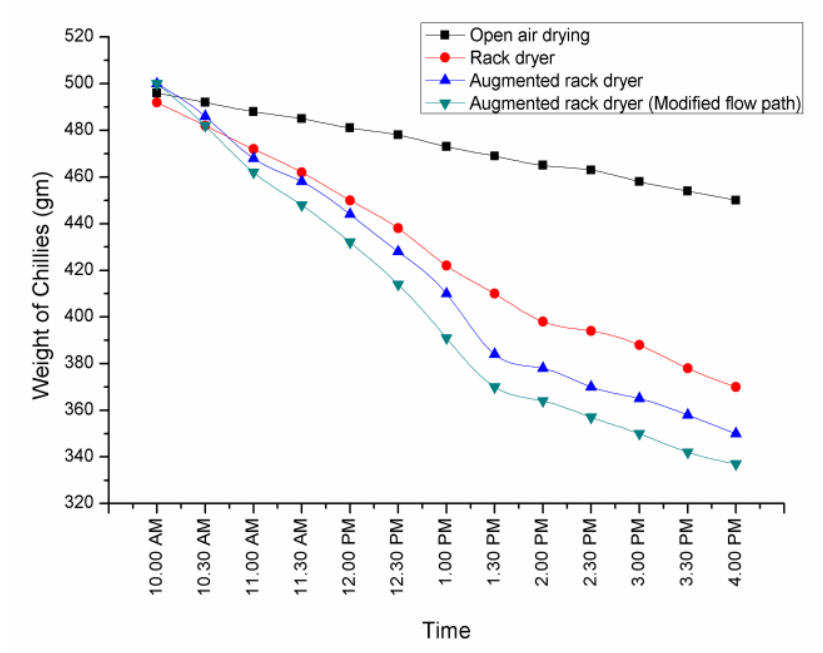

Figure 16. Loss of weight of chillies in various drying methods

\subsection{Energy analysis}

Specific energy consumption (SEC) for this solar drying is obtained using the ratio of energy input to the dryer to mass of water removed from the product.

$$
m_{w}=\frac{m_{i}\left(m_{1}-m_{2}\right)}{\left(100-m_{2}\right)}
$$

$\mathrm{m}_{\mathrm{w}}=$ mass of water removed from the product in $\mathrm{kg}$

$\mathrm{m}_{\mathrm{i}}=$ mass of the product in $\mathrm{kg}$

$\mathrm{m}_{1}=$ initial moisture content in $\mathrm{kg}$

$\mathrm{m}_{2}=$ final moisture content in $\mathrm{kg}$

SEC for various drying methods is calculated and presented in the Figure 17. The specific energy consumption in drying of Capsicum frutescens is decreased by $30-35 \%$ in the new approach in comparison to open drying which is clearly understood from the Figure 17.

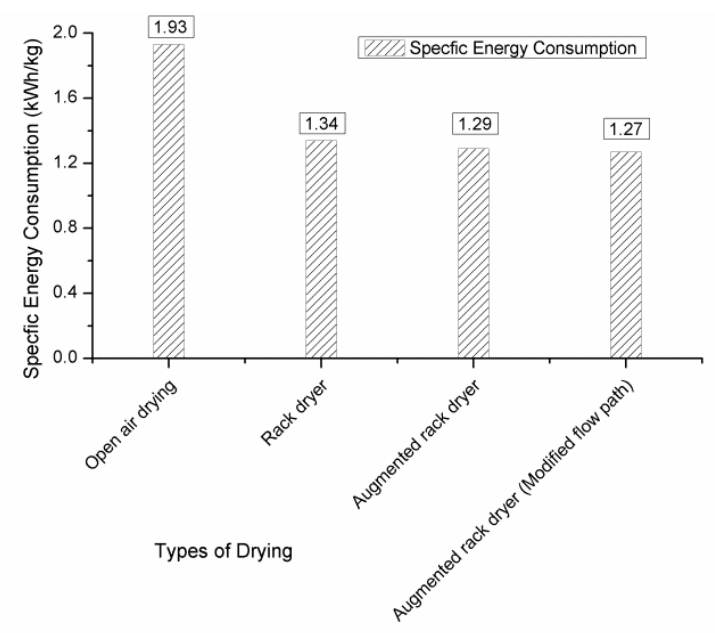

Figure 17. Specific energy consumption in various drying methods

\subsection{Exergy analysis}

The exergy values are calculated based on steady flow system concept $[23,24]$. The mass flow rate of air is found to be $0.012 \mathrm{~kg} / \mathrm{s}$ and the specific heat of air is taken as $1005 \mathrm{~J} / \mathrm{kgK}$.

Exergy for steady flow system is given by Eq. (2).

$$
E_{x e r}=m_{a} C_{p a}\left[\left(T-T_{a}\right)-T_{a} \ln \frac{T}{T_{a}}\right]
$$

Exergy at the inlet section is given by Eq. (3).

$$
E_{x e r i n}=m_{a} C_{p a}\left[\left(T_{i n}-T_{a}\right)-T_{a} \ln \frac{T_{i n}}{T_{a}}\right]
$$

Exergy at the chamber outlet is given by Eq. (4).

$$
E_{\text {xerout }}=m_{a} C_{\text {pa }}\left[\left(T_{\text {out }}-T_{a}\right)-T_{a} \ln \frac{T_{\text {out }}}{T_{a}}\right]
$$

The exergy losses are calculated using Eq. (5).

$$
E_{\text {xerloss }}=\left[E_{\text {xerin }}-E_{\text {xerout }}\right]
$$

The exergy efficiency is expressed as the ratio of exergy utilized in the drying of the product to exergy in the drying air supplied and it is given by Eq. (6).

$$
\eta_{\text {exer }}=\frac{E_{\text {xerout }}}{E_{\text {xerin }}}
$$

The exergy efficiency of the drying chamber is found to be in the range of $4 \%-45 \%$ with an average of $16 \%$ for Capsicum frutescens is shown in the Figure 18. 


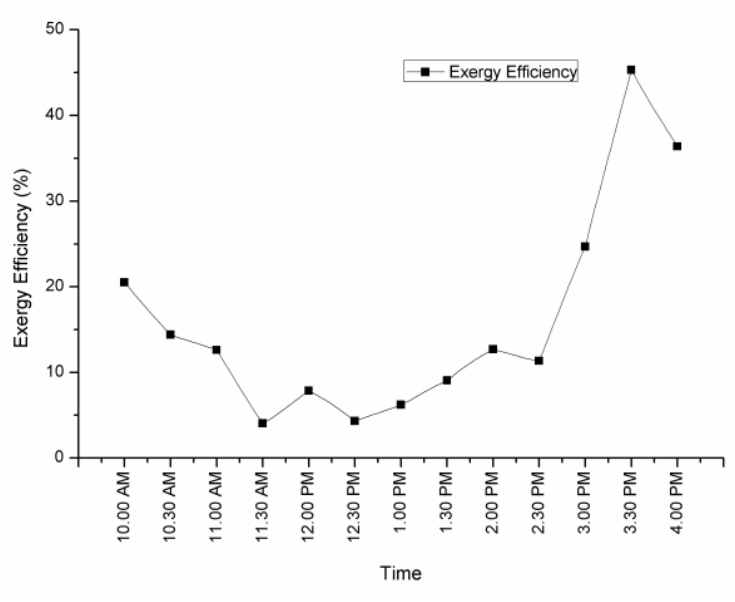

Figure 18. Exergy efficiency of augmented drier with modified flow path

\section{CONCLUSIONS}

Heat transfer augmentation through water-in-glass evacuated tube coupled with parabolic trough is studied for the drying of Capsicum frutescens. The drying rate is found to be $62 \%$ higher in the rack dryer compared to open solar drying. With the developed augmentation technique, the drying rate is found to be $7 \%$ higher than that of rack dryer without augmentation technique. The inclination provided at the bottom of the cabinet rather than at the top leads to the elimination of stagnant air in bottom region. In addition, this enhances the drying rate of the chillies further by $3 \%$ in augmented rack dryer. The drying rate achieved in the present study is limited to capsicum frutescens which may vary for other crops. There is a possibility for further enhancement in heat transfer when water in evacuated tube is replaced by alternate heat transfer fluids.

\section{ACKNOWLEDGMENT}

The authors would like to appreciate the support of Renewable Energy Laboratory and Automatic Solar Radiation Monitoring Station at Kongu Engineering College, Erode, Tamilnadu, India.

\section{REFERENCES}

[1] Abubakkar, A., Selvakumar, P., Rajagopal, T., Tamilvanan, A. (2020). Development of concentrating dish and solar still assembly for sea water desalination. Materials Today: Proceedings. https://dx.doi.org/10.1016/j.matpr.2020.03.043

[2] Chabane, F., Bensahal, D., Brima, A., Moummi, N. (2019). Solar drying of drying agricultural product (Apricot). Mathematical Modelling of Engineering Problems, 6(1): 92-98. https://doi.org/10.18280/mmep.060112

[3] Ekechukwu, O.V., Norton, B. (1999). Review of solarenergy drying systems II: An overview of solar drying technology. Energy Conversion and Management, 40(6): 615-655. 8904(98)00093-4
[4] Fudholi, A., Sopian, K., Ruslan, M.H., Alghoul, M., Sulaiman, M. (2010). Review of solar dryers for agricultural and marine products. Renewable and Sustainable Energy Reviews, 14(1): 1-30. https://doi.org/10.1016/j.rser.2009.07.032

[5] Mohanraj, M., Chandrasekar, P. (2009). Performance of a forced convection solar drier integrated with gravel as heat storage material for chili drying. Journal of Engineering Science and Technology, 4(3): 305-314.

[6] Kumar, R.A., Babu, B.G., Mohanraj, M. (2016). Thermodynamic performance of forced convection solar air heaters using pin-fin absorber plate packed with latent heat storage materials. Journal of Thermal Analysis and Calorimetry, 126(3): 1657-1678. https://dx.doi.org/10.1007/s10973-016-5665-6

[7] Saxena, A., Srivastava, G., Tirth, V. (2015). Design and thermal performance evaluation of a novel solar air heater. Renewable Energy, 77: 501-511. https://doi.org/10.1016/j.renene.2014.12.041

[8] Pangavhane, D.R., Sawhney, R., Sarsavadia, P. (2002). Design, development and performance testing of a new natural convection solar dryer. Energy, 27(6): 579-590. https://doi.org/10.1016/S0360-5442(02)00005-1

[9] Jain, D., Tewari, P. (2015). Performance of indirect through pass natural convective solar crop dryer with phase change thermal energy storage. Renewable Energy, 80: 244-250. https://doi.org/10.1016/j.renene.2015.02.012

[10] Aboul-Enein, S., El-Sebaii, A., Ramadan, M., El-Gohary, H. (2000). Parametric study of a solar air heater with and without thermal storage for solar drying applications. Renewable Energy, 21(3-4): 505-522. https://dx.doi.org/10.1016/S0960-1481(00)00092-6

[11] Barnwal, P., Tiwari, G. (2008). Grape drying by using hybrid photovoltaic-thermal (PV/T) greenhouse dryer: An experimental study. Solar Energy, 82(12): 1131-1144. https://dx.doi.org/10.1016/j.solener.2008.05.012

[12] Mustayen, A., Mekhilef, S., Saidur, R. (2014). Performance study of different solar dryers: A review. Renewable and Sustainable Energy Reviews, 34: 463470. https://doi.org/10.1016/j.rser.2014.03.020

[13] Tyagi, V., Panwar, N., Rahim, N., Kothari, R. (2012). Review on solar air heating system with and without thermal energy storage system. Renewable and Sustainable Energy Reviews, 16(4): 2289-2303. https://doi.org/10.1016/j.rser.2011.12.005

[14] Jain, D., Jain, R.K. (2004). Performance evaluation of an inclined multi-pass solar air heater with in-built thermal storage on deep-bed drying application. Journal of Food Engineering, 65(4): 497-509. https://doi.org/10.1016/j.jfoodeng.2004.02.013

[15] Jain, D. (2005). Modeling the system performance of multi-tray crop drying using an inclined multi-pass solar air heater with in-built thermal storage. Journal of Food Engineering, $\quad 71(1)$ : 44-54. https://doi.org/10.1016/j.jfoodeng.2004.10.016

[16] Hossain, M., Woods, J., Bala, B. (2005). Optimisation of solar tunnel drier for drying of chilli without color loss. Renewable Energy, 30(5): 729-742. https://doi.org/10.1016/j.renene.2004.01.005

[17] Lamnatou, C., Papanicolaou, E., Belessiotis, V., Kyriakis, N. (2012). Experimental investigation and thermodynamic performance analysis of a solar dryer using an evacuated-tube air collector. Applied Energy, 
94:

232-243.

https://dx.doi.org/10.1016/j.apenergy.2012.01.025

[18] Kaewkiew, J., Nabnean, S., Janjai, S. (2012). Experimental investigation of the performance of a largescale greenhouse type solar dryer for drying chilli in Thailand. Procedia Engineering, 32: 433-439. https://doi.org/10.1016/j.proeng.2012.01.1290

[19] Srisittipokakun, N., Kirdsiri, K., Kaewkhao, J. (2012). Solar drying of Andrographis paniculata using a parabolic shaped solar tunnel dryer. Procedia Engineering, 32: 839-846. https://doi.org/10.1016/j.proeng.2012.02.021

[20] Selvakumar, P., Somasundaram, P., Thangavel, P. (2014). Performance study on evacuated tube solar collector using therminol D-12 as heat transfer fluid coupled with parabolic trough. Energy Conversion and Management, 85: 505-510.

https://doi.org/10.1016/j.enconman.2014.05.069

[21] Fudholi, A., Sopian, K., Othman, M.Y., Ruslan, M.H.
(2014). Energy and exergy analyses of solar drying system of red seaweed. Energy and Buildings, 68: 121129. https://doi.org/10.1016/j.enbuild.2013.07.072

[22] El-Sebaii, A., Shalaby, S. (2013). Experimental investigation of an indirect-mode forced convection solar dryer for drying thymus and mint. Energy Conversion and Management, 74: 109-116. https://dx.doi.org/10.1016/j.enconman.2013.05.006

[23] Rabha, D., Muthukumar, P., Somayaji, C. (2017). Energy and exergy analyses of the solar drying processes of ghost chilli pepper and ginger. Renewable Energy, 105: 764-773. https://doi.org/10.1016/j.renene.2017.01.007

[24] Tamilvanan, A., Balamurugan, K., Vijayakumar, M. (2019). Effects of nano-copper additive on performance, combustion and emission characteristics of Calophyllum inophyllum biodiesel in CI engine. Journal of Thermal Analysis and Calorimetry, 136(1): 317-330. https://doi.org/10.1007/s10973-018-7743-4 